\title{
Abuso sexual extrafamiliar: percepções das mães de vítimas
}

\author{
Extra-familial sexual abuse: perceptions \\ of the victims' mothers
}

\author{
Clarissa De ANTONI \\ Maria Angela Mattar YUNES \\ Luisa HABIGZANG $^{3}$ \\ Sílvia Helena KOLLER'
}

\begin{abstract}
Resumo
Abuso sexual extrafamiliar é uma forma de violência em que crianças e adolescentes são vitimizados por adultos sem laços parentais. A análise ecológica permite observar esse fenômeno de forma multicausal e compreender interações de risco e proteção em contextos variados. Participaram deste estudo qualitativo três mães de meninas que foram vítimas desse tipo de abuso. O instrumento utilizado foi uma entrevista semidirigida. Os resultados revelaram aspectos semelhantes aos encontrados no abuso intrafamiliar: síndrome do segredo, gratificação secundária e singularidades de interação e organização das famílias. Há elementos semelhantes nas infâncias de mães e filhas: perda dos pais, contínua privação material e sofrimento por abandono e maus tratos. Quanto à percepção da situação abusiva, as mães culpam as filhas, apontando suas características de "fraqueza" ou "impulsividade" e não responsabilizam o agressor, o que fomenta a vulnerabilidade das filhas diante de situações de abuso.
\end{abstract}

Unitermos: Abuso sexual. Abuso sexual extrafamiliar. Crenças. Famílias em situação de risco.

\begin{abstract}
Extrafamilial sexual abuse is a form of violence where children and adolescents are victimized by adults with no parental connection. Ecological analysis allows us to observe the multicausality of the phenomenon and to understand risk and buffer mechanisms in different contexts. Three mothers of girls who had suffered this type of abuse participated in this qualitative study. The instrument used was a semi-structured interview. The results point to the presence of similar aspects to those of intrafamilial abuse: syndrome of secrecy, secondary gratification, peculiarities of the interaction and organization offamilies. There are similar elements in the infancies of mothers and children: loss of parents; constant material deprivation and suffering through abandonment and maltreatment. The situation experienced by the daughters is perceived by their mothers as characteristics of "weakness" and "impulsivity" and they do not attribute blame to the aggressor, which increases their daughters'vulnerability when faced with abusive situations.
\end{abstract}

Uniterms: Sexual abuse. Extrafamilial sexual abuse. Beliefs. Families in risk situations.

$\boldsymbol{\nabla \nabla \nabla \nabla}$

1 Universidade Federal de Ciências da Saúde de Porto Alegre, Instituto de Psicologia. R. Sarmento Leite, 245, Sala 207, 90050-170, Porto Alegre, RS, Brasil. Correspondência para/Correspondence to: C. De ANTONI. E-mail: <clarissadeantoni@yahoo.com.br>.

2 Universidade Federal do Rio Grande, Departamento de Educação e Ciências do Comportamento, Centro de Estudos Psicológicos de Meninos e Meninas. Rio Grande, RS, Brasil.

3 Universidade Federal do Rio Grande do Sul, Curso de Especialização em Psicoterapia Cognitivo-Comportamental. Porto Alegre, RS, Brasil. Apoio: Conselho Nacional de Desenvolvimento Científico e Tecnológico, Edital MCT-CNPqMMS-SCTIE-DECIT\CT-Saúde-No 0722005. 
Este artigo visa a tecer considerações teóricas e de pesquisa sobre o abuso sexual extrafamiliar contra adolescentes. Para tanto, serão abordados os conceitos de abuso sexual intra e extrafamiliar, a análise ecológica dos fatores de risco e de proteção presentes nesses contextos e a percepção das mães das vítimas a partir da análise de três casos de abuso extrafamiliar.

O Estatuto da Criança e do Adolescente (ECA) (1990), em seu Art. 5, preconiza claramente: "Nenhuma criança ou adolescente será objeto de qualquer tipo de negligência, discriminação, exploração, violência, crueldade e opressão, punido na forma da lei qualquer atentado, por ação ou omissão, aos direitos fundamentais". Tal afirmativa, documentada na forma de lei e, portanto, escrita de maneira impositiva, não garante a inexistência de expressões comportamentais e relacionais constatadas na realidade social brasileira. As diferentes formas de violência flagradas contra a criança e o adolescente operam em diferentes culturas e classes sociais e preocupam filósofos, sociólogos, psicólogos e outros cientistas sociais.

Apesar de a literatura sobre violência contra crianças e adolescentes contar com mais de cem anos (Aded, Dalcin, Moraes \& Cavalcanti, 2006), e a primeira publicação sobre violência física ter sido escrita em 1868 pelo médico legista francês Ambroise Tardieu (Cecconello, De Antoni \& Koller, 2003; Roche, Fortin, Labbe, Brown \& Chadwick, 2005), a preocupação com as sequelas provocadas pela violência é relativamente recente, como também a necessidade de uma visão interdisciplinar para observar o fenômeno (Neves \& Romanelli, 2006).

Em relação ao abuso sexual, as contribuições científicas significativas nessa área têm sido editadas no periódico Child Abuse and Neglect. No Brasil, há um crescente movimento de conscientização acadêmica e da população em geral sobre o abuso e suas consequências. Isso vem sendo fomentado por programas governamentais, como, por exemplo, a criação do antigo Programa Sentinela (Barbosa, Paim, Koshima \& Xavier, 2001) e atual Serviço de Enfretamento à Violência, ao Abuso e à Exploração Sexual de Crianças e Adolescentes, desenvolvido no âmbito do Centro de Referência Especializado de Assistência Social (CREAS); o Plano Nacional de Enfrentamento da Violência Sexual Infanto-Juvenil (2002); o Programa de Prevenção, Assistência e 98 Combate à Violência Contra a Mulher (2003), entre outros - e por grupos de estudos filiados a universidades federais, estaduais e particulares.

Essas ações de conscientização são decorrentes dos índices e das estimativas alarmantes de abuso sexual contra crianças e adolescentes. Segundo instituições de pesquisa na área, cerca de 165 casos por dia são denunciados (Associação Brasileira Multidisciplinar de Proteção à Criança e ao Adolescente - ABRAPIA). 0 relatório de 2007 do serviço Disque Denúncia Nacional de Abuso e Exploração Sexual Contra Crianças e Adolescente, sob a coordenação da ABRAPIA, aponta que 27,8\% dos casos delatados estão relacionados à violência sexual. Isto é, o Disque Denúncia Nacional realiza, em média, 2159 atendimentos diários, tendo recebido e encaminhado, de maio de 2003 a janeiro de 2007, 28630 denúncias de todo o país.

Por suas peculiaridades, o abuso sexual deixa marcas que podem influenciar a construção da identidade das suas vítimas e dificultar as interações sociais (Habigzang \& Caminha, 2004). Portanto, deve-se olhar para essa questão como um fenômeno que ultrapassa o âmbito da clínica individual e que merece ser tratado como uma preocupação da área da Saúde Coletiva (Habigzang, Koller, Azevedo \& Machado, 2005).

O abuso sexual, principalmente em crianças e adolescentes, tem sido tema de estudos que o conceituam, em suas delimitações e qualificações, não apenas de forma diagnóstica, mas também por uma necessidade de despertar na população geral a consciência sobre as condições abusivas às quais está exposta em algumas comunidades. O abuso sexual é definido como um "ato ou jogo sexual" configurado por uma relação em que há o agressor ou abusador, que possui um nível de desenvolvimento psicológico, físico e sexual superior ao da vítima. Em função disso, essa forma de relação revela um desequilíbrio de poder e de desejo, sempre em prol do abusador (Amazarray \& Koller, 1998; Gabel, 1997; Habigzang \& Caminha, 2004).

Segundo Furniss (1993), a criança é vista pelo abusador como um instrumento de excitação, e não como uma pessoa. Outro aspecto relevante da conceituação de abuso sexual é o fato de não necessariamente ocorrer o contato físico-sexual. Segundo o relatório do Disque Denúncia (ABRAPIA, 2007), são categorizadas como formas abusivas as sugestões sexuais, que são relatos que descrevem situações nas 
quais são feitos à criança ou adolescente comentários sexualmente provocantes ou se lhe mostram fotos ou vídeos pornográficos. Portanto, a exposição da criança e do adolescente a situações que envolvam voyeurismo, exibicionismo ou assédio verbal também é considerada forma sexual abusiva.

Além disso, existe a exploração sexual por meio da comercialização do corpo, que envolve prostituição e pornografia, pela Internet ou na produção e veiculação de vídeos, impressos ou apresentações ao vivo). Também são comuns os relatos no Disque Denúncia (ABRAPIA, 2007) de situações de exploração sexual comercial, em que a violência sexual acontece de forma sistemática e visando ao lucro. Outras formas abusivas são o tráfico de pessoas nacional e internacional e o turismo sexual.

Nos estudos sobre esse fenômeno, são encontrados basicamente dois contextos diferenciados: o intrafamiliar e o extrafamiliar. O intrafamiliar é o abuso que ocorre no âmbito familiar, com pessoas próximas e com laços afetivos ou de parentesco, como pai, padrasto ou outros; e o extrafamiliar, comumente cometido por pessoas desconhecidas da vítima ou sem vínculo afetivo nem de parentesco com ela.

O abuso intrafamiliar é apontado por dados demográficos nacionais e internacionais como o mais comum e compõe cerca de $80 \%$ dos casos denunciados (Kristensen, Oliveira \& Flores, 1999). Pode-se justificar, assim, o intenso número de publicações que envolvem pesquisas e estudos de caso sobre a dinâmica familiar, suas características e consequências para o desenvolvimento socioemocional das vítimas (Furniss, 1993; Habigzang et al., 2005). Essa produção vem propagando-se especialmente nos últimos quarenta anos (Aded et al., 2006).

Outra categoria encontrada é o abuso sexual extrafamiliar, que não ocorre necessariamente no âmbito das relações familiares. Geralmente é ocasionado por um adulto sem laços parentais e que pode ser conhecido ou não da família. Sempre é aludido àquelas crianças e adolescentes que vivem em situação de rua, e geralmente está relacionado à exploração sexual comercial, como podemos observar em materiais divulgados por programas governamentais de combate à exploração sexual (vide, por exemplo: Refazendo Laços de Proteção, Instituto WCF-Brasil, 2006).
Além disso, são encontradas afirmações que equiparam abuso extrafamiliar à exploração sexual comercial de crianças e adolescentes como se fossem o mesmo fenômeno (ABRAPIA, 2007). O abuso sexual extrafamiliar ocorre geralmente em locais próximos da residência da vítima e é perpetrado por desconhecidos ou por pessoas com uma relação pouco intensa com a família da criança. As vítimas mais frequentes são as adolescentes, jovens e adultas do sexo feminino. Ao pesquisar o tema do abuso sexual extrafamiliar em diferentes bases de dados (SciELO, google acadêmico, BVS-Psi), pode-se constatar a escassez de produção bibliográfica não apenas em língua portuguesa, mas também em outros idiomas.

\section{Bioecologia do desenvolvimento humano}

Para compreender o fenômeno do abuso sexual extrafamiliar, propomos uma análise ecológica das interações familiares e sociais, por meio da Teoria Bioecológica do Desenvolvimento Humano (Bronfenbrenner, 1996; Bronfenbrenner \& Morris, 1998). O foco principal são os mecanismos de risco e de proteção que levam à situação de vulnerabilidade psicossocial dessas vítimas.

Para Bronfenbrenner e Morris (1998), a análise ecológica deve conter quatro núcleos inter-relacionados: a pessoa, o processo, o contexto e o tempo. Evidencia-se a importância do contexto e dos processos na compreensão da dinâmica familiar diante do abuso sexual que acontece fora do ambiente familiar. Bronfenbrenner (1996) define contexto como o meio ambiente no qual a pessoa se relaciona e que é concebido como uma estrutura de encaixes, contidos entre si, que compõem o micro-, o meso-, o exo- e o macrossistema. O microssistema é o contexto imediato no qual estão estabelecidas as inter-relações, as atividades compartilhadas, o desempenho de papéis e as relações de poder. A família pode ser compreendida como um microssistema, assim como o ambiente onde a criança sofre o abuso sexual. O mesossistema é um conjunto de microssistemas inter-relacionados na vida das pessoas, como a escola, igreja, local de trabalho, vizinhança, comunidade, entre outros. É no mesossistema que identificamos a rede de apoio social e afetiva ou comprovamos sua precariedade, principalmente em situações nas quais a criança necessita de apoio e proteção. 
Em cada microssistema que a pessoa frequenta, ela necessita desempenhar papéis específicos e interagir de forma adequada àquele ambiente. Essa circulação entre os microssistemas, que acarreta a mudança de papéis, é denominada de transição ecológica. O exossistema é formado pelos diversos ambientes dos quais a pessoa não participa direta ou ativamente, mas que influencia suas decisões, como, no caso das crianças vítimas de abuso, o conselho tutelar ou os programas governamentais de atendimento a crianças vítimas de abuso sexual. Os macrossistemas contêm ideologias, culturas, subculturas, políticas e crenças que regem determinada sociedade da qual a pessoa faz parte.

Assim, os referidos contextos ecológicos são núcleos de extrema importância para a compreensão do fenômeno em pauta, pois nos auxiliam a ampliar a visão linear da violência somente como uma forma relacional entre duas pessoas, centrada apenas na psicopatologia do agressor ou da vítima. Não se trata, portanto, de um fenômeno apenas relacional, mas também psicossocial. Então, pode-se pensar que, de forma geral, estar inserido em um contexto de miserabilidade econômica e de privação afetiva influencia as interações e pode vir a ser um fator de risco para a manifestação de violências.

Outro conceito primordial são os processos, compreendidos como a maneira pela qual as pessoas interpretam os eventos por meio de sentimentos e aprendizados. O processo proximal, que se relaciona às interações progressivamente mais complexas da pessoa com outras, e com objetos e símbolos, é um conceito central na teoria bioecológica. Esse processo pode produzir dois tipos de efeitos: a competência, que advém da aquisição e desenvolvimento de conhecimentos, habilidades e capacidades para conduzir e direcionar seu próprio comportamento; e a disfunção, manifestação recorrente da dificuldade em manter o controle e a integração do comportamento em diferentes domínios do desenvolvimento (Bronfenbrenner, 2005).

\section{Método}

Esse estudo fez parte de uma pesquisa intitulada "Avaliação e intervenção psicológica para meninas vítimas de violência sexual", que teve como objetivo 100 aplicar e avaliar a efetividade de um modelo de ava- liação e intervenção psicológica para meninas, entre 9 e 16 anos, vítimas de violência sexual. Dentre outras metas, o projeto buscou verificar experimentalmente a efetividade do modelo de grupoterapia cognitivo-comportamental proposto por Habigzang e Caminha (2004), com a utilização de técnicas cognitivas e comportamentais (psicoeducação, treino de inoculação do estresse e prevenção à recaída) na redução de sintomas de depressão, ansiedade, transtorno do estresse pós-traumático e na reestruturação de crenças distorcidas com relação ao abuso sexual. Portanto, as adolescentes foram inseridas em um programa de intervenção psicoeducacional em grupo que visava a amenizar o sofrimento vivenciado pela situação abusiva e a buscar estratégias conjuntas para a não revitimização (Habigzang, Hatzenberger, Dala Corte, Stroher \& Koller, 2006).

A presente investigação surgiu em paralelo à execução do referido programa, por meio de um projeto intitulado "Intervenção com cuidadores de crianças e adolescentes vítimas de abuso sexual" (De Antoni, Yunes, Habigzang \& Koller, 2006). Para tal investigação, foram realizados contatos informais com as mães de algumas das meninas no mesmo local de atendimento das adolescentes. As mães foram convidadas para uma entrevista semiestruturada individual com objetivo de investigar questões relacionadas aos padrões de organização familiar, aos processos de comunicação, à rede de apoio e ao sistema de crenças, de acordo com o roteiro elaborado por De Antoni et al. (2006). As entrevistas duraram cerca de uma hora e foram realizadas no mesmo local e horário de atendimento das filhas. Essas respostas subsidiaram as ações e os temas da intervenção grupal com cuidadores.

Especificamente para esse estudo, foram selecionados, descritos e analisados três casos de mães biológicas. O delineamento da pesquisa seguiu os princípios dos Estudos de Casos Múltiplos (Yin, 2005). Esta pesquisa seguiu as determinações da Resolução no 196/96, do Ministério da Saúde, com consentimento li-vre e esclarecido dos participantes e aprovação pelo Comitê de Ética da Universidade Federal do Rio Grande do Sul em (protocolo no 2004299).

As categorias de análise apresentadas a seguir surgiram a partir da análise textual discursiva das narrativas das entrevistas (Moraes, 1999), método que propõe uma análise rigorosa e criteriosa do corpus obtido, com 
a intenção de compreender os fenômenos, e não de comprovar ou refutar hipóteses, possibilitando, assim, a renovada compreensão do conjunto dos relatos.

\section{Descrição dos Casos}

Caso 1: a família é formada pelo casal e cinco filhos entre 13 anos e um ano e seis meses de idade. A mãe revela que sua mãe faleceu quando ela tinha quatro anos, e que viveu "jogada e rolando no mundo". Seu relato evidencia uma infância de muitas privações e de violência física. Aos 15 anos, engravidou de um rapaz, que não assumiu a filha; logo em seguida, casou-se com um primo, seu atual marido. O casal esteve desempregado, e recentemente o marido iniciou um trabalho como vigia noturno. No período em que ambos estavam desempregados, a mãe afirmou ter passado por dificuldades financeiras, e que, por vezes, não havia nenhum tipo de alimento para seus filhos, nem auxílio governamental para sobrevivência. Ela relata que pedia "dinheiro" para seu vizinho, cerca de R\$2,00 para comprar carcaça de frango para fazer sopa. Sempre pedia para a filha, na época com 11 anos, levar o bilhete e trazer o dinheiro. O vizinho tinha mais de 70 anos e, de acordo com o relato dessa mãe, "era respeitado"na comunidade por ter condições financeiras melhores do que as dos demais moradores. Ela comenta que ele estaria envolvido com atos ilícitos, dos quais obtinha sua renda. Era constante essa prática de "ajudar" as vizinhas com dinheiro ou comida, principalmente as meninas, que iam em busca de doces, que ele sempre Ihes oferecia quando o visitavam. A mãe eventualmente fazia limpeza ou lavava as roupas desse homem, atividades pelas quais era remunerada. A versão da mãe para a situação do abuso é a de que ela não sabia o que acontecia quando a filha ia buscar dinheiro ou doces. Revela que a menina contou para a diretora da escola que esse homem invadiu seu quarto à noite e a levou para sua casa, onde ocorreu o abuso, mas a mãe, inicialmente, não acreditou, pois julgava a filha "mentirosa". Somente acreditou no relato da menina após outras denúncias contra esse homem.

Caso 2: a família é formada pelo casal e duas filhas. A mais velha é casada e tem um filho. A caçula tem 11 anos. A mãe cuida da casa e o pai tem uma oficina de conserto de carros. A infância da mãe foi mar- cada pela perda dos pais, privações econômicas e maus tratos por parte dos irmãos. Em relação ao abuso sexual contra sua filha de 11 anos, diz que "não aconteceu nada". Em sua percepção, não houve abuso, "pois não chegaram a transar, tirar a virgindade dela". Os pais souberam da situação por um bilhete anônimo, deixado no portão da casa e descoberto por parentes. $O$ bilhete dizia: "A. e L. cuidem da B. Tem alguém abusando dela, não deixem ela ir pra rua". A mãe alega não saber quem seria o abusador, pois a menina não quis Ihe contar. A menina continuava saindo sozinha, e a mãe justifica: "Ninguém sabelidar com isso, se a gente prender agora, ela vai reagir. Ela quer mostrar que tem mais poder que a gente.... Segundo informações prestadas pela menina, o abusador é um vizinho, mais velho, dono de uma mercearia, que oferecia doces em troca de situações de voyeurismo e exibicionismo. Além disso, cometia atos abusivos com intercurso sexual com outra menina na presença dessa criança.

Caso 3: a família é formada pelo casal (mãe e padrasto) e duas filhas. A mãe está desempregada, mas, na época, trabalhava como auxiliar de serviços gerais. O padrasto também está desempregado e faz trabalhos eventuais. A infância da mãe foi marcada por uma disciplina severa e o comportamento rígido dos seus pais. Quando uma das filhas tinha 13 anos, começou a sair de casa, sem dizer para onde ia, e a família passava alguns dias sem notícias. A mãe sabia do seu envolvimento com drogas e até recebeu ameaças de morte da filha por parte das pessoas com quem ela andava. A menina "falou por cima e deu sinais" sobre um "amigo" mais velho (de 40 a 50 anos), que a ajudava. A menina visitava-o frequentemente; certo dia, ele the ofereceu drogas; segundo a mãe, "... ele só passava a mão no corpo dela". Depois desse episódio, a menina voltou para a casa desse homem para buscar os documentos que ela havia esquecido, quando o Conselho Tutelar fez uma averiguação, pois o homem sofrera outras denúncias por estupro. O Conselho Tutelar abrigou a menina como medida de proteção. A mãe acredita que o abuso ocorreu por que a filha "tinha uma cabeça muito fraca... ela me mentiu, eu não podia fazer mais nada".

Diante desses casos pesquisados, três perspectivas de análise dos resultados mostraram-se relevantes para este estudo e resultam em questionamentos: 1) A situação de pobreza em que as famílias 
brasileiras vivem é um possível fator de risco para o abuso sexual extrafamiliar? 2) O processo de transição entre o ambiente familiar e a exposição a situações de risco pode facilitar o abuso sexual e, consequentemente, a exploração comercial? 3) Quais as percepções, crenças e sentidos atribuídos pelas cuidadoras (mães) em relação ao abuso vivenciado por suas filhas?

\section{Pobreza e desigualdade social: as possíveis relações com as situações de abuso sexual extrafamiliar}

O primeiro questionamento é: a situação de pobreza em que as famílias brasileiras vivem pode tornar-se fator de risco para o abuso sexual extrafamiliar? Muitos autores reconhecem que pobreza e miséria são importantes fatores de risco universal (Luthar, 1999; Luthar \& Zigler, 1991) e que a privação econômica é uma das principais fontes de risco sociocultural para o desenvolvimento humano (Fincham, Grych \& Osborne, 1994; Garbarino \& Abramowitz, 1992). Entretanto, é preciso implementar o conhecimento científico sobre os fatores de risco que se apresentam nesses contextos, ou seja, é necessário identificar e compreender as ameaças sociais e as adversidades que permeiam a vida e o cotidiano das comunidades de baixa renda. Cabe ressaltar que esses fatores são processuais, dinâmicos e subjetivos, pois o que seria risco na condição de pobreza para um indivíduo, grupo familiar ou comunidade, pode ser percebido como desafiador e mobilizador de recursos para outros.

Em relação ao abuso sexual extrafamiliar em famílias de nível socioeconômico baixo, De Antoni e Koller (2001) observaram que muitas crianças envolvidas nessa prática abusiva e suas famílias por vezes sobrevivem da relação de troca do corpo da criança ou adolescente por bens materiais de primeira necessidade, tais como comida, moradia etc., e não, especificamente, por uma remuneração em dinheiro. Essas constatações evidenciam a violência provocada pela miserabilidade econômica e afetiva à qual está exposta essa população. No caso 1, essa situação é visível quando a menina vai à casa do abusador levar bilhetes pedindo dinheiro para comprar "carcaça de frango", talvez o único alimento para uma família composta por sete pessoas. Observa-se a questão do poder financeiro do abusador sobre a condição desfavorecida das vítimas, como nos casos

1022 e 3.
Portanto, o olhar ecológico possibilita ver as diversas formas de manifestação da violência que podem desencadear o abuso extrafamiliar. Talvez uma delas seja a violência estrutural. De acordo com Minayo (1990, p.290), a violência estrutural é "aquela que nasce no próprio sistema social, criando as desigualdades e suas consequências, como a fome, o desemprego e todos os problemas sociais com que convive a classe trabalhadora". É uma das formas mais expressivas de violência social e sua compreensão requer um pensamento com foco nos macrossistemas (Bronfenbrenner, 1996), sem deixar de lado as demais dimensões contextuais de influência no desenvolvimento humano. Ao se tratar da questão macrossistêmica, percebe-se que formas atuais de expressão de violência se enquadram "nos sistemas econômicos, culturais e políticos abusivos que conduzem à opressão de grupos, classes, nações e indivíduos aos quais são negadas as conquistas da sociedade, tornando-os mais vulneráveis que outros ao sofrimento e à morte" (Minayo, 1994, p.8). Isso significa pensar nos valores, nas crenças, nas práticas e nas tradições que reiteram e coíbem oportunidades de bem estar e de qualidade de vida a todos aqueles que integram os sistemas sociais em uma comunidade.

É possível pensar, também, na esteira do raciocínio ecológico e sistêmico, nas expressões de violência estrutural microssistêmica, que ocorrem por meio das consequências observadas no cotidiano de muitas famílias, que são: a obrigação de viver com salários irrisórios ou sem renda fixa, o abandono das crianças pela impossibilidade de sustentá-las, a situação de crianças fora do ambiente escolar por falta de escolas ou de condições de enviá-las ao estabelecimento de ensino, a falta de cuidados adequados de saúde, terá falta de saneamento básico na comunidade e a perda progressiva dos direitos sociais e civis adquiridos (Minayo, 1994). Nos casos analisados, temos essas situações descritas nos relatos de duas famílias, que vivem em situação de pobreza. São famílias que não controlam ou monitoram os filhos, e a rua passa a ser um local de sobrevivência.

Essas formas de viver constituem-se "ambientes socialmente tóxicos", que retratam as privações sociais e culturais às quais essas populações de baixa renda estão submetidas (Garbarino \& Abramovitz, 1992), muitas vezes, por ciclos de gerações. Esses autores referem-se à pobreza e aos riscos socioculturais como 
ameaças ao desenvolvimento de crianças e adolescentes, exemplificados como "falta de comida, de afeto, de professores carinhosos, de boas condições de atendimento médico e de valores coerentes com progresso intelectual e competência social" (p.35).

Paugan (1999) distingue pobreza de exclusão social ao enfocar que o fenômeno da pobreza geralmente remete a questões relativas a populações com dificuldades de sobreviver devido à baixa renda ou à renda insuficiente. Segundo o autor, o termo "exclusão" mostra-se mais adequado para enfatizar processos com múltiplas causas, dentre as quais é sublinhado o desemprego como um dos fatores desencadeantes dos sentimentos de "desqualificação social". É muito comum observar que a perda do emprego nas famílias pobres é associada a outras perdas (do casamento, dos bens materiais etc.), e que ela pode causar isolamento e sensação de vergonha. O desemprego é uma forma de violência estrutural, que pode, portanto, ser a causa de outras tantas formas de violência social e interpessoal.

O trabalho antropológico de Sarti (1996) afirma que, na condição de pobreza, "a noção de ser trabalhador dá ao pobre uma dimensão positiva (p.67), e que "o trabalho é o instrumento que viabiliza a vida familiar" (p.73). Portanto, o trabalho dimensionado pela empregabilidade constitui um elemento de honra, com rendimento moral, e que entrelaça as relações familiares e fortalece o sistema moral. Compreender como se processam as relações familiares em casos prolongados de desemprego de responsáveis adultos em famílias de baixa renda pode contribuir para entender a violência interpessoal como reflexo, ou a intensificação da violência estrutural (Minayo \& Souza, 1999). Em duas das famílias pesquisadas, observamos a desqualificação profissional dos cuidadores e a submissão a subempregos ou ao desemprego. Considerando-se que esse fator seria o exossistema de crianças e adolescentes na ótica da ecologia do desenvolvimento humano (Bronfenbrenner, 1996), temos a constatação teórica dessas implicações na vida familiar.

\section{Transição entre o microssistema familiar e os ambientes de risco}

A segunda perspectiva de análise está relacionada ao processo de transição entre o ambiente familiar e a exposição dessas crianças e adolescentes a situações de risco. Indaga-se se a condução desse processo de transição ecológica poderia levar ao abuso sexual extrafamiliar e, consequentemente, à exploração comercial.

Embora a perspectiva da condição de pobreza possa ser entendida como fator de risco para as crianças ou adolescentes em relação à exposição a situações abusivas, não é um fator determinante. Nesses casos, a situação de pobreza pode ser compreendida com fator coadjuvante em relação à estrutura e funcionamento familiar. Percebe-se, nesses casos, que o abuso extrafamiliar ultrapassa a fronteira das relações intrafamiliares por ser cometido por abusadores sem vínculo familiar, porém conhecidos da família, por exemplo, vizinhos ou conhecidos que estão em condições financeiras melhores do que as da família.

Entretanto, essas famílias podem, de certa forma, compactuar, muitas vezes de forma não consciente, com o risco de abuso. Essa transição pode ser motivada explicitamente pela própria família, como no caso 1 (a mãe manda bilhetes para o abusador), ou de forma implícita, como nos casos 2 (a mãe não sabe onde a filha está) e 3 (a mãe sabe que a filha tem um amigo mais velho e que a menina vive na rua). Podemos inferir duas hipóteses, que não são excludentes, para essa afirmativa, e que podem levar à ocorrência dessa transição: a primeira está relacionada à busca de bens materiais; a segunda, à busca de experiências adversas que possibilitem explorar, por parte da adolescente, outros microssistemas. Assim, a adolescente busca outros microssistemas que proporcionem, ilusoriamente, o acesso a melhores condições materiais ou a satisfação imediata de suas necessidades materiais, como alimentos ou drogas. A presença ou o contato com o abusador, no primeiro momento, torna-se uma solução imediata para amenizar as necessidades de consumo ou de sobrevivência, sem que a menina tenha condições de mensurar o processo abusivo estabelecido a partir desse envolvimento inicial.

Conjuntamente a essa necessidade material, encontra-se um comportamento da vítima em se colocar em uma situação de risco, sem ao menos percebê- la como tal. Essas meninas estão em um momento de vulnerabilidade, que pode ser ocasionado pela própria adolescência (curiosidade, necessidade de autonomia, 
pensamento mágico de que nada Ihes pode acontecer, entre outros comportamentos característicos dessa fase do ciclo vital). Além disso, esses momentos podem evidenciar a precariedade afetiva e de comunicação nas relações familiares e a presença de um modelo parental não protetivo existente. Assim, a tendência é repetir em suas experiências adversas, em outros contextos, esse modelo relacional não protetivo aprendido em sua família e que, por sua vez, foi vivenciado também por suas mães em suas histórias de vida. No caso das mães em questão, podem-se constatar três aspectos importantes em comum: 1) a infância marcada por perdas significativas, como a dos pais; 2) a privação material; 3) os maus tratos (abuso físico, emocional e abandono) sofridos por parte de seus cuidadores.

Esses fatores de risco associados podem influenciar negativamente o desenvolvimento da parentalidade desses progenitores. Pessoas que não tiveram um modelo parental protetivo, amoroso e cuidadoso podem não saber como atentar para as necessidades de seus filhos e, assim, podem não promover processos de comunicação eficazes e o sentimento de coesão na díade mãe-filha. Assim, as filhas não encontram um espaço para compartilhar suas angústias, vivências e desejos. A figura paterna parece pouco participativa ou emocionalmente ausente nessas famílias. Talvez esse seja um dos canais de transição para ambientes abusivos.

O encontro entre a vítima e o abusador torna-se uma situação de perigo. Há o desejo da adolescente de sobreviver ou de ter conforto e de conhecer outros contextos. Nesse interjogo relacional, percebe-se que o abuso sexual extrafamiliar apresenta aspectos semeIhantes ao abuso cometido no microssistema familiar, como a síndrome do segredo e a gratificação secundária (Furniss, 1993). A síndrome do segredo diz respeito ao comportamento do agressor, que, para manter o abuso e não ser revelado, cerca-se de uma rede de mentiras, ameaças e barganhas com a vítima. Em todos os casos, as meninas foram ameaçadas caso revelassem a situação de abuso, e as denúncias partiram de outros ambientes: no caso 1, da escola; no caso 2, do bilhete anônimo; no caso 3, do Conselho Tutelar.

A gratificação secundária, então, é o "pseudo" ganho da vítima, recebido por meio de subornos e de 104 recompensas em troca do abuso ou do sigilo. Nos casos acompanhados, pode-se observar que as vítimas ganhavam bens materiais, como chocolates, dinheiro e drogas. Segundo Furniss (1993), esse tipo de vinculação torna-se danosa para os futuros relacionamentos da criança, que entende que as relações afetivas, principalmente as amorosas/sexuais, são pautadas pelo estabelecimento de barganhas materiais. Diante de um adolescente, que está em busca da sua identidade social e sexual, isso se torna ainda mais agravante.

Os processos proximais entre a adolescente e o abusador são marcados por uma relação gradual. Ambos estabelecem uma relação de trocas em que a vítima sempre está em desvantagem. O que, inicialmente, pode parecer uma vinculação, torna-se uma violação de seus direitos, pela violação do seu corpo e dos seus desejos. Portanto, a transição para um microssistema abusivo sexualmente ocorre, nesses casos, em função da falta de proteção de outros microssistemas (como o familiar), incapazes de suprir as necessidades materiais ou afetivas dessas adolescentes.

\section{Percepções e crenças das mães das vítimas e os sentidos atribuídos por elas}

A terceira perspectiva abordada possibilita conhecer as percepções e as crenças das cuidadoras (mães) e os sentidos atribuídos por elas em relação ao abuso vivenciado por suas filhas. Cada microssistema familiar apresenta características de interação particulares e específicas, de acordo com as características das pessoas nele envolvidas. No entanto, observam-se alguns aspectos semelhantes nas histórias e nos relatos dessas mães, principalmente em relação à percepção sobre a ocorrência do abuso, o comportamento das filhas e seu papel nesse processo.

Em relação ao abuso, encontra-se no discurso dessas mães o fato de elas minimizarem, banalizarem ou naturalizarem a violência vivida pelas filhas. Desconhecem que as situações que envolvem voyeurismo, exibicionismo ou toques são sexualmente abusivas. Pensam, portanto, que o abuso sexual só ocorre quando há intercurso genital. Como no caso 2, em que a mãe afirma: "pois não chegaram a transar, tirar a virgindade dela". Segundo Plummer (2006), a descoberta pela mãe do abuso sofrido pela filha pode ser compreendida mais como um processo do que como um evento. As mães 
podem, portanto, reagir de várias formas: sentindo-se responsáveis e culpadas ou, de forma não apropriada, percebendo o abuso como um evento de vida "normal".

Em seu estudo, Plummer constatou também que as mães têm dificuldades em aceitar ou acreditar no fato, o que gera desconfiança na denúncia da criança. As mães deste estudo relatam o fato de forma superficial, não demonstrando preocupação com a gravidade das consequências da situação. Essa forma de perceber os abusos revela a falta de conhecimento dessas mães, o que poderá permitir que as filhas fiquem expostas a outras situações abusivas.

Percebemos que, ao relatarem o abuso, as mães constroem um discurso que culpa a menina/vítima. As filhas são vistas como "fracas" (caso 1 e 3: "tinha uma cabeça muito fraca") ou "incontroláveis" (casos 2 e 3). As mães não compreendem as filhas como adolescentes em período de formação de identidade e esperam que elas tenham atitudes de autoproteção. Essa fraqueza que as mães percebem pode estar relacionada à vulnerabilidade e a outras características presentes, como o comprometimento do autoconceito, a falta da rede de apoio e a ausência do sentimento de coesão familiar, aspectos que poderiam promover resiliência (Yunes, 2003). Além disso, ao culpar as filhas, essas mães não responsabilizam o agressor.

As mães parecem, por fim, não compreender o papel de apoio emocional e protetivo que a família deve desempenhar no desenvolvimento de crianças e adolescentes. É possível que as histórias de abandono e maus-tratos dessas mães contribuam para a dificuldade de proteger e de dar apoio afetivo a suas filhas. Nas entrevistas, elas demonstram estar mais preocupadas com seu possível envolvimento jurídico do que com o bem- estar das filhas, como a mãe do caso 1, que estava preocupada com os "bilhetes" escritos por ela, que estavam anexados ao processo. No caso 2, a mãe alegou desconhecer quem era o abusador e frisou: "ela [filha] me mentiu, eu não podia fazer mais nada". No caso 3, a preocupação era manter a filha abrigada para realizar um "tratamento das drogas", serviço inexistente no local de abrigagem.

\section{Considerações Finais}

A prevenção do abuso sexual extrafamiliar no início da adolescência é tão importante quanto a prevenção de qualquer outra forma de violência. Assim, merece especial atenção dos pesquisadores, já que indica ser um precursor para a exploração sexual comercial infanto-juvenil. Há ainda um campo emergente de estudos sobre as práticas sociais individuais, familiares e institucionais em relação ao abuso sexual extrafamiliar, bem como sobre as ideologias presentes nesse macrossistema.

As análises desses estudos serão norteadoras de políticas públicas de atendimento, proteção e prevenção, de forma geral, dos maus-tratos à infância e à adolescência. Assim, deve-se relevar ainda a prioridade na construção de programas públicos de atenção e apoio às famílias em desvantagem social e econômica, já que o cenário e as vicissitudes da pobreza podem ser marcadores dos acontecimentos analisados neste trabalho. Programas de intervenção devem fornecer informação sobre desenvolvimento humano, reflexão e discussão sobre práticas educativas e estilos parentais, situações abusivas vivenciadas no cotidiano dessas famílias e, principalmente, sobre as crenças distorcidas do papel do abusador/abusado. Trabalhar essas temáticas possibilitará importantes "pontos de virada" nas interações, na organização e na comunicação familiar, e esse trabalho deve ser pautado transversalmente pelos diferentes segmentos da rede de apoio social e afetivo.

\section{Referências}

Aded, N. L. O., Dalcin, B. L. G. S., Moraes, T. M., \& Cavalcanti, M. T. (2006). Sexual abuse in children and adolescents: Review of 100 years of literature. Revista de Psiquiatria Clínica, 33 (4), 204-213.

Amazarray, M., Koller, S. H. (1998). Alguns aspectos observados no desenvolvimento de crianças vítimas de abuso sexual. Psicologia: Reflexão e Crítica, 11 (3), 546-555.

Associação Brasileira Multidisciplinar de Proteção à Criança e ao Adolescente. (2007). Disque denúncia nacional de abuso e exploração sexual contra crianças e adolescentes: disque 100. Brasília: Autor.

Barbosa, H., Paim, I., Koshima, K., \& Xavier, S. (2001). Programa Sentinela Nacional. In Centro de Defesa da Criança e do Adolescente Yves de Roussan. Construindo uma história: tecnologia social de enfrentamento à violência sexual contra crianças e adolescentes (pp.239-241). Bahia: Cedeca-BA.

Bronfenbrenner, U. (1996). Ecologia do desenvolvimento humano: experimentos naturais e planejados. Porto Alegre: Artes Médicas.

Bronfenbrenner, U. (2005). Making human beings human: bioecological perspectives on human development. Thousand Oaks: Sage. 
Bronfenbrenner, U., Morris, P. A. (1998). The ecology of developmental processes. In W. Damon \& R. M. Lerner (Eds.), Handbook of child psychology: theoretical models of human developmental (pp.993-1027). New York: John Wiley.

Cecconello, A. M., De Antoni, C., \& Koller, S. H. (2003). Práticas educativas, estilos parentais e o abuso físico intrafamiliar. Psicologia em Estudo, 8, 45-54.

De Antoni, C., \& Koller, S. H. (2001). O psicólogo ecológico no contexto institucional: uma experiência com meninas vítimas de violência. Psicologia: Ciência e Profissão, 21(1),14-36.

De Antoni, C., Yunes, M. A., Habigzang, L. F., \& Koller, S. H. (2006). Intervenção com cuidadores de crianças e adolescentes vítimas de abuso sexual. Manuscrito não-publicado, Universidade Federal do Rio Grande do Sul, Porto Alegre.

Estatuto da Criança e do Adolescente. (1990). Lei no 8.069, de 13 de agosto de 1990. Porto Alegre: Corag.

Fincham, F., Grych, J. H., \& Osborne, L. N. (1994). Does marital conflict cause child maladjustment? Directions and challenges for longitudinal research. Journal of Family Psychology, 8, 128-140.

Furniss, T. (1993). Abuso sexual da criança: uma abordagem multidisciplinar. Porto Alegre: Artes Médicas.

Gabel, M. (1997). Crianças vítimas de abuso sexual. São Paulo: Summus.

Garbarino, J., \& Abramowitz, R. H. (1992). Sociocultural risk and opportunity. In J. Garbarino. Children and families in the social environment ( $2^{\text {nd }}$ ed., pp.35-70). New York: Aldine de Gruyter.

Habigzang, L. F., \& Caminha, R. M. (2004). Abuso sexual contra crianças e adolescentes: conceituação e intervenção clínica. São Paulo: Casa do Psicólogo.

Habigzang, L. F., Hatzenberger, R., Dala Corte, F., Stroher, F., \& Koller, S. H. (2006). Grupoterapia cognitivo-comportamental para meninas vítimas de abuso sexual: descrição de um modelo de intervenção. Psicologia Clínica, 18 (2), 163-182.

Habigzang, L. F., Koller, S. H., Azevedo, G., \& Machado, P. X. (2005). Abuso sexual e dinâmica familiar: aspectos observados em processos judiciários. Psicologia: Teoria e Pesquisa, 21 (3), 1-8.

Instituto WCF-Brasil. (2006). Refazendo laços de proteção: ações de prevenção ao abuso è exploração sexual comercial de crianças e adolescentes. São Paulo: Cenpec. Disponível em www.associaçao sãolucas.org.br

Kristensen, C. H., Oliveira, M. S., \& Flores, R. Z. (1999). Violência contra crianças e adolescentes na grande Porto Alegre: pode piorar? In Fundo das Nações Unidas para a Infância (Org.), Violência doméstica (pp.104-117). Brasília: Unicef.
Luthar, S. S. (1999). Poverty and children's adjustment. In A. E. Kazdin (Ed.), Developmental clinical psychology and psychiatry (Vol.41, pp.128). London: Sage.

Luthar, S. S., \& Zigler, E. (1991). Vulnerability and competence: a review of research on resilience in childhood. American Journal of Orthopsychiatry, 61 (1), 6-22.

Moraes, R. (1999). Análise de conteúdo. Educação, 37, 7-32.

Minayo, M. C. S. (1990). A violência na adolescência: um problema de saúde pública. Cadernos de Saúde Pública, 6 (3), 278-292.

Minayo, M. C. S. (1994). Violência social sob a perspectiva da saúde pública. Cadernos de Saúde Pública, 10 (1), 4-19.

Minayo, M. C. S., \& Souza, E. R. (1999). É possível prevenir a violência? Reflexões a partir do campo da saúde pública. Ciência e Saúde Coletiva, 4 (1), 7-32.

Neves, A. S., \& Romanelli, G. (2006). A violência doméstica e os desafios da compreensão interdisciplinar. Estudos de Psicologia (Campinas), 23 (3), 299-306. doi: 10.1590/S010 3-166X2006000300009.

Paugan, S. (1999). As formas elementares da pobreza nas sociedades europeias. In M. P. B. Veras (Org.), Por uma sociologia da exclusão social: o debate com Serge Paugan (pp.81-96). São Paulo: Educ.

Plano Nacional de Enfrentamento da Violência Sexual Infanto-Juvenil. (2002). Garantia de direitos (Vol. 5: Subsídios). Brasília: Ministério da Justiça.

Programa de Prevenção, Assistência e Combate à Violência Contra a Mulher. (2003). Diálogos sobreviolência doméstica e de gênero: construindo políticas públicas. Brasília: Secretaria Especial de Políticas para as Mulheres.

Plummer, C. A. (2006). The discovery process: what mothers see and do in gaining awareness of the sexual abuse of their children. Child Abuse and Neglect: The International Journal, 30 (11), 1227-1237.

Roche, A. J., Fortin, G., Labbe, J., Brown, J., \& Chadwick, D. (2005). The work of Ambroise Tardieu: the first definitive description of child abuse. Child Abuse and Neglect: The International Journal, 4 (29), 325-334.

Sarti, C. A. (1996). A familia como espelho: um estudo sobre a moral dos pobres. Campinas: Autores Associados.

Yin, R. K. (2005). Estudo de caso: planejamento e métodos. Porto Alegre: Bookman.

Yunes, M. A. M. (2003). Psicologia positiva e resiliência: o foco no indivíduo e na família. Psicologia em Estudo, 8 (Especial), 75-84.

Recebido em: 22/6/2009

Versão final reapresentada em: 15/9/2010

Aprovado em: 29/10/2010 